\title{
“MITOLOGIAS" EM TORNO DA NOVIDADE TECNOLÓGICA EM EDUCAÇÃO
}

\author{
Rosa MARIA Bueno FischeR*
}

RESUMO: O ensaio discute algumas mitologias em torno do uso das tecnologias digitais no campo da educação, com base em autores como Sherry Turkle, Michel Foucault, Marilena Chauí e Muniz Sodré. Discutem-se temas relativos à constituição de subjetividades, no interior do novo cenário ético dado pelas diversas práticas educacionais e comunicacionais, propiciadas pelo acesso às redes sociais e a experiências com uma série de situações e objetos virtuais, vividas especialmente pelos grupos mais jovens, de diferentes camadas sociais.

Palavras-chave: Tecnologias digitais. Redes sociais. Sociabilidade. Subjetividade. Mitologia.

\section{Some MYthologies ABOUt NEW TECHNOLOGIES AND EDUCATION}

ABSTRACT: In this essay, we discuss some myths about digital technologies on education, working with concepts of Michel Foucault, Sherry Turkle, Marilena Chauí and Muniz Sodré about those issues. This paper focuses on the subjectivities construction, considering the new ethical scenery related with educational practices on communication, virtual life, especially by young people, from various strata of society.

Key words: Digital technologies. Social networks. Sociability. Subjectivity. Mythology.

\section{Mythologies autour de la nouveauté TECHNOLOGIQUE EN ÉDUCATION}

RÉSUMÉ: L'essai débat de quelques mythologies sur l'usage des nouvelles technologies de l'information et de la communication, dans l'éducation, à partir d'auteurs comme Sherry Turkle, Michel Foucault, Marilena Chauí et Muniz Sodré. Nous débattons le thème de la constitution de la subjectivité au sein du nouveau cadre éthique créé par les diverses pratiques éducatives,

* Doutora em Educação e professora do Curso de Pedagogia e do Programa de Pós-Graduação em Educação da Universidade Federal do Rio Grande do Sul (UFRGS) E-mail: rosabfischer@terra.com.br 
issues de l'accès aux réseaux sociaux et des expériences avec une série de situations et objets virtuels, vécues particulièrement par les groupes les plus jeunes, de différentes couches sociales.

Mots-clés: Technologie. Réseau social. Sociabilité. Subjectivité. Mythologie.

\section{"Mitologias" em torno da novidade tecnológica na educação}

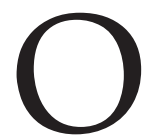

objetivo deste texto é apresentar e discutir um conjunto daquilo que chamaremos de "mitologias", relacionadas ao "amor à novidade tecnológica" na educação. Problematizamos aqui alguns mitos como os da cooperação, da facilidade de comunicação, da necessária transformação (da verticalidade para a horizontalidade) nas relações entre professor e aluno, entre outros. Valemo-nos dos estudos Sherry Turkle, de Michel Foucault, de Marilena Chauí e de Muniz Sodré, entre outros, para pensar sobre a produção e circulação de determinados discursos - como o do mito da técnica -, na constituição de subjetividades e de certo "cenário ético" hoje, com base no "bem em si" dos objetos técnicos no âmbito da informação e da comunicação em rede.

Ao escolher o termo "mitologias", fazemos uma referência clara à obra de Roland Barthes, cujo título é exatamente Mitologias, e que reúne estudos produzidos nos anos de 1950 (Barthes, 2009); neles, o autor elabora análises de imagens, fotografias, peças publicitárias, cenas políticas e culturais diversas, enfim, relatos daquele momento, a partir de um questionamento ao modo como certas afirmações se tornavam naturalizadas como verdade. Para tanto, usou o conceito de mito - mito como linguagem; ou, mais precisamente, mito como fala ideológica. E assim compôs as suas "mitologias", atacando com arte e pensamento o modo como certos relatos se faziam "naturalmente verdadeiros" na cultura europeia de meados do século XX. Inspirados, portanto, nesse criativo modo de pensar barthesiano, também nos perguntamos sobre verdades que muitas vezes já não questionamos, quando se trata das formas contemporâneas de comunicação e de informação - particularmente no que se refere ao uso das tecnologias digitais, das chamadas redes sociais e das múltiplas formas de fazer educação a distância em nosso país.

Um dos propósitos deste breve ensaio, portanto, é questionar a rapidez e a facilidade com que assumimos muitas vezes o amor à tecnologia por ela mesma, replicando modos de fazer educação, muitos deles já bastante questionados no âmbito da pesquisa acadêmica e da prática pedagógica. Estaríamos, como referiu Barthes há mais de meio século, operando também neste caso com a linguagem do mito? Estaríamos esvaziando e empobrecendo o que é da ordem do histórico, nas relações entre educação e tecnologias digitais, aceitando sem qualquer mediação os ditos que significam tais práticas como naturalmente boas? Também discutimos 
neste espaço questões urgentes levantadas por alguns pesquisadores, a respeito de novas sociabilidades e complexas relações com o "outro" na sociedade digital. Tais questões remetem a temas e a conceitos fundamentais na formação de professores e alunos: visibilidade pública do privado, comunicação digital versus conectividade, poder e exposição de si, verdade e informação na web, ética da presença distante, experiência genuína e experimentação digital, intimidade e isolamento, solidão e felicidade no espaço digital, o "eu" colaborativo e a relação a distância entre alunos e professores.

\section{Ética, criação e tecnologias: um debate antigo}

Seguramente, um dos textos mais citados, quando se coloca na mesa o debate sobre técnica, poder e cultura, é o clássico de Walter Benjamin, A obra de arte na era da reprodutibilidade técnica (Benjamin, 1993a). Voltamos a ele inúmeras vezes, quando nos questionamos sobre os efeitos das tecnologias de reprodução dos bens culturais, porque também Benjamin se questionava sobre a complexidade dessa mudança nos modos de apropriação da arte (e, por extensão, das diferentes criações humanas). De um lado, o filósofo até celebrava a decadência da aura da obra de arte, na medida de um acesso maior a ela, em virtude de sua multiplicação. Isso implicaria (e implica ainda hoje, a meu ver) uma conquista do ponto de vista político: afastamo-nos da arte como culto, pois ela sem dúvidas está mais próxima dos diferentes públicos e grupos sociais. Por outro lado, no entanto, Benjamin nos alertava para o fato de que haveria uma substituição cumulativa, do relato pela informação, da informação pela sensação - o que significava, na sua análise, uma verdadeira atrofia da experiência (Benjamin, 1993b).

No cerne dessa crítica da qual não cessamos de nos valer, quando pensamos no cruzamento entre novas tecnologias e educação, estão alguns temas básicos. Dentre eles, destaco, com base em Benjamin, a autenticidade das relações dos sujeitos com a vida social e as formas genuínas de transmissão. Comecemos por esta: a transmissão não se contenta com a mera comunicação que se faz a alguém, com o mero relato de algo que ocorreu com esta ou aquela pessoa. Antes, tal gesto implica uma espécie de encarnação do ocorrido, naquele que narra, para proporcionar aos que escutam algo que é, justamente, da ordem da experiência. Ou seja, dá-se a experiência no ato mesmo do encontro entre o que narra e aquele que acolhe a narração. Em outras palavras, para além de uma "vivência" que é contada ao outro, trata-se aqui de um acontecido que transformou o sujeito-narrador, de tal forma que, ao assumir a tarefa criativa de transmissão, nesse gesto mostra-se um "algo a mais" do acontecido, situação que produz no ouvinte também uma nova experiência, passível de ser narrada para si mesmo e para um novo outro. 
Não vamos aqui nos estender na discussão a respeito da experiência - tema tão amplo e já tão discutido, a partir dos mais diferentes pontos de vista teóricos -, embora eu entenda que sobre ele ainda precisemos pensar e pesquisar muito, de modo particular quando nos debruçamos sobre os usos que crianças e jovens fazem das novas tecnologias de informação e comunicação, disponíveis em nossos tempos - aliás, uma das obras mais completas e bem escritas sobre o assunto é o livro Cantos da experiência. Variaciones modernas sobre un tema universal (Jay, 2009).

Se os modos de transmissão e narração se oferecem a nós, hoje, como fundamentais em nossos debates educacionais, eles sem dúvida não deixam de tocar no tema da autenticidade; interessa-nos aqui pensar a autenticidade não só no que se refere à originalidade da obra de arte (segundo Benjamin), mas também, e com maior ênfase, no que tange à qualidade da relação dos sujeitos contemporâneos com a quantidade imensa de objetos técnicos a que têm acesso, bem como à qualidade da comunicação e da informação digital, a partir do mergulho irreversível (ao que parece) nas diferentes redes virtuais, que animam cotidianamente nossas relações interpessoais.

Cabe perguntar: $\mathrm{O}$ que efetivamente muda quando a exposição de nós mesmos se dá num lugar em que tempo e espaço se esgarçam e não têm limites, como a web? Como nos preservamos como sujeitos de experiência, na medida em que nosso tempo é quase inteiramente dedicado a "postar" o que estamos fazendo, a divulgar as imagens do que vivenciamos e a compartilhar as opiniões que "curtimos", num sem cessar interminável? Certamente, já não se trata de falar de uma vida ou de uma criação "original", mas de um novo modo de estar no mundo e que se torna verdade para cada um de nós, como se de fato não pudesse ser diferente do que está sendo.

Em outras palavras, entendo que estamos às voltas com discussões já bem conhecidas, sobre a relação entre homem e técnica, ética e ciência, reprodução e criação, artificialidade e autenticidade. Dizer que tais debates são antigos não significa afirmar que eles são os mesmos, que estão postos da mesma forma, tanto quanto nas primeiras décadas do século XX. Talvez possamos dizer que, desde Benjamin, oscilamos - ora apocalípticos, ora integrados (Eco, 2008) - entre posições francamente humanistas e outras radicalmente críticas, quanto ao que fazemos de nossas relações com as tecnologias audiovisuais e digitais, e seus respectivos produtos e práticas diárias. Mas também essas oscilações se apresentam, a cada vez, de um modo distinto.

Podemos destacar, por exemplo, pensadores como Gilbert Simondon (2007), que faz questionamentos a certo humanismo romântico, presente nas diferentes críticas à técnica e na defesa de uma filosofia centrada num ser humano supostamente despojado de suas relações com a natureza e seu próprio fazer - ou seja, despojado de sua "existência técnica" (Rodríguez, 2007). Simodon realiza uma análise das oscilações que referimos anteriormente, usando uma metodologia que podemos 
aproximar da perspectiva foucaultiana, na medida em que faz uma espécie de genealogia das relações entre homem e técnica e as respectivas posições discursivas, assumidas em diferentes épocas e por distintos pensadores, sem buscar para isso sua "verdadeira origem" (cf. Foucault, 2008).

Para Simondon (op. cit.), os seres humanos operam no mundo a partir de uma característica muito especial - a de fazer a matéria se multiplicar no mundo, criando objetos e sistemas técnicos; ao mesmo tempo, se posicionam diante dessas criações, ora produzindo fantasias de liberação (como a afirmação comum, hoje, de que a internet nos libera para o acesso a toda e qualquer informação, rompendo as amarras de processos educativos presenciais e dominados por supostos detentores do saber), ora imaginando que a técnica subjugará tudo o que for da ordem do genuinamente humano (como os enunciados referentes a uma juventude que dedica um tempo bem maior à comunicação virtual do que às relações tête-à-tête, e às respectivas perdas intersubjetivas daí decorrentes). Para Simondon, "individuar" os objetos técnicos corresponde a fazê-los sofrer um processo de concretização - o que, por sua vez, diz respeito a um fazer humano que se torna repetível, representável e analisável, exatamente por meio desses mesmos produtos criados por homens e mulheres, em diferentes espaços e tempos (cf. Rodríguez, op. cit.).

Ora, a obra de Simondon configura uma crítica explícita aos teóricos da Escola de Frankfurt e às suas formulações sobre a razão instrumental da técnica moderna da primeira metade do século XX; também configura uma declaração de guerra (como escreve Rodríguez, no prólogo ao livro de Simondon) à clássica conferência de Martin Heidegger (2002) sobre o mundo da técnica, de 1954; seu posicionamento encontra-se no fato de que estaríamos diante de certos humanismos um tanto fáceis, que se negariam a ver o que é próprio da realidade humana nos objetos e sistemas técnicos, especialmente nas máquinas. No Brasil, estudiosos como Arlindo Machado alinham-se às mesmas argumentações de Simondon, lembrando que, quando o homem inventa uma máquina, qualquer que seja, ela passa a ser não um mero artefato mecânico, mas sim "a materialização de um processo mental, um pensamento que tomou corpo e ganhou existência autônoma". Ou seja, ao criar uma máquina, dá-se "forma material a um processo de pensamento" (Machado, 1996, p. 34).

Machado vai além, ocupado em pensar as máquinas que ele chama de "máquinas semióticas", aquelas destinadas a operar com nossas representações: tais máquinas (como as que produzem fotos, vídeos, programas de tevê, jornais, filmes, sites na internet), de acordo com o autor,

(...) desempenham papel fundamental na atividade simbólica do homem contemporâneo, porque elas têm uma eloquência própria, que pode inclusive ser mais decisiva que a utilização particular que lhes dá cada um dos seus usuários. Elas "falam", elas 
determinam modos de percepção, elas incutem ideologias pelo quem têm de "saber" materializado em suas peças e circuitos, pela sua maneira particular de tornar sensível o mundo de que elas são a mediação e pela sua específica resolução do problema de codificação desse mesmo mundo. (Machado, op. cit., p. 34-35)

Veremos, na seção a seguir, que o sofisticado desenvolvimento das tecnologias digitais, das relações humanas com robôs e tantos outros objetos automatizados, aliado à ampliação das redes sociais e de um número quase infinito de sites e de postagem de vídeos, fotos e textos na internet, acabou por trazer outras e diferenciadas pesquisas e análises. Estas convidam o estudioso da área de educação a novamente colocar na mesa perguntas sobre como nos tornamos o que somos hoje, no que se refere às trocas intersubjetivas, às práticas de transmissão de experiências, às formas de criação simbólica, às relações com a alteridade - todas elas fundamentais, quando se trata de pensar na formação ética e estética de crianças e jovens. Duas pensadoras - Marilena Chauí e a norte-americana Sherry Turkle - conduzem nossas perguntas e discussões. Por outro lado, considerações do conhecido pesquisador da área de comunicação, Muniz Sodré, também nos ajudam a construir a argumentação a respeito de indagações sobre o foco, muitas vezes tão mais acentuado na instrumentalidade e na utilidade da técnica e das tecnologias na educação, do que na capacidade quase ao infinito das possibilidades de inventividade e criação simbólica e na transmissão da experiência - o que nos faz trazer sempre à presença as discussões de Benjamin e de Heidegger.

\section{Alone together}

Quando lemos o subtítulo do livro Alone together, de Sherry Turkle (2011) "Por que esperamos mais da tecnologia do que uns dos outros" (trad. nossa) -, talvez possamos pensar, um tanto desavisados, que estamos diante de mais uma "humanista romântica", a que se referiu Simodon na obra comentada anteriormente. O fato é que Turkle é pesquisadora e professora do famoso Massachusetts Institute of Technology (MIT), nos Estados Unidos. Ela foi não só fundadora como é, ainda, diretora do MIT Iniciative on Techonology and Self, responsável por inúmeras pesquisas sobre questões que envolvem as íntimas relações das pessoas com as tecnologias digitais. Escreveu vários livros, entre eles The second self e Life on the screen, os quais, com Alone together, mostram a trajetória de uma pensadora que ousou desafiar os próprios colegas do MIT, quando se indaga sobre o que ela chama de "the robotic moment", considerado crucial na constituição do sujeito contemporâneo, especialmente quando falamos das gerações mais jovens.

Falando por dentro de uma instituição de ponta, mergulhada em toda a produção que ali se desenvolve, no que concerne às mais sofisticadas tecnologias de 
comunicação e informação, a pesquisadora se propôs, nos últimos anos, a usar uma metodologia de investigação que pudesse reunir, simultaneamente, a sensibilidade da etnógrafa e a da psicóloga clínica. Focada no público jovem, ela recolheu para esse último livro anotações de entrevistas, escutas clínicas, conversas, observações antropológicas livres do cotidiano (por exemplo, uma singela fila na entrada de um museu), e foi compondo um quadro das angústias, expectativas, indagações e certezas de estudantes de high schools e de colleges, também de seus pais, nos Estados Unidos - num total de 450 sujeitos, 300 dos quais crianças.

Os testemunhos de jovens estudantes, nos últimos anos, levaram Turkle a questionar alguns mitos que nós, na área da educação, ainda insistimos em reiterar, quando sustentamos uma euforia positiva e quase salvacionista, permitida supostamente pela relação com os meios digitais, com os objetos tecnológicos como os tablets, o já "clássico" PC, os smartphones, bem como com os jogos eletrônicos, os milhares de sites da internet, os vídeos do You Tube, entre tantos outros objetos técnicos e seus produtos. Muniz Sodré relaciona essa mitologia contemporânea ao fato de que estaríamos diante de um novo cenário ético, caracterizado pela "prevalência do bem tecnológico", "que recalca quaisquer outros aspectos moral e socialmente negativos na rede cibernética ou a evidência de que a 'liberdade' na rede consiste simplesmente na seleção de conexões dentro de um jogo combinatório de possibilidades" (Sodré, 2011, p. 203).

Turkle nos ajuda a ter certa reserva com tal excesso de otimismo, que ela mesma já cultivou nos anos de 1980, quando escreveu Life on screen, quanto às possibilidades de abertura às pessoas, oferecidas pela tela do computador conectado na rede, no sentido da constituição de identidades online. A identificação com os avatares dos jogos digitais mostrava-se promissora então, mas Turkle já observava algo inquietante nos depoimentos das crianças e jovens que entrevistou naqueles anos: alguns falavam em "vida real", referindo-se a seus avatares; conectados com as janelas dos e-mails, do arquivo das pesquisas para a escola, dos games favoritos - tudo ao mesmo tempo -, muitos diziam que a vida real dos avatares "não passava de mais uma janela no computador" (Turkle, 2011, p. XII). O que significava para aqueles sujeitos uma vida real que não passava de uma "janela" no computador?

Aos poucos, a pesquisadora do MIT decidiu que era imprescindível estudar quais mudanças efetivamente estariam ocorrendo em nossa sociedade, na qual, de fato, já temos mais de uma geração que pode ser chamada de "nativos digitais". Suas perguntas passaram a referir-se à complexa produção de novas subjetividades em curso - portanto, a uma espécie de "perigo" de nosso tempo, conforme sugere Foucault numa de suas entrevistas a Dreyfus e Rabinow, sobre a publicação dos volumes II e III de sua História da sexualidade. Foucault dizia a seus entrevistadores que se ocupava do tema do sujeito dos anos de 1980 não exatamente porque estivesse buscando 
soluções para o presente, a partir de um suposto modelo de vida, encontrado nos gregos clássicos. Foucault desejava fazer uma genealogia das problematizações que até então a sociedade ocidental se vinha propondo.

Da mesma forma que Turkle, hoje, Foucault propunha não a busca de alternativas, mas um posicionamento que ele chamou de "hiperativismo pessimista". “Minha opinião - sintetizava Foucault - é que nem tudo é ruim, mas tudo é perigoso, o que não significa exatamente o mesmo que ruim. Se tudo é perigoso, então temos sempre algo a fazer (...). Acho que a escolha ético-política que devemos fazer a cada dia é determinar qual é o principal perigo" (Foucault, 2010, p. 299). Pois bem, Turkle mostra-se atenta a alguns perigos - que procuro articular a alguns excessos de otimismo em nós -, referentes ao alargamento sem limites dos espaços e dos tempos, no ambiente virtual que visitamos todos os dias ao navegarmos na internet. A autora nos diz, na apresentação do livro, que o grande deslocamento feito por ela consiste em focar não mais na relação one-to-one com o computador, mas sim nas relações mais amplas das pessoas umas com as outras. Emerge para a autora uma preocupação com os modos de subjetivação na experiência com a cultura digital, na medida dos efeitos que essas práticas trazem para nossos modos de compreender e viver a alteridade.

Numa argumentação semelhante, Sodré reivindica a necessidade de olhar com mais cuidado para o cenário certamente espetacular das possibilidades de conectividade digital em nosso tempo. $\mathrm{O}$ autor sugere que se tomem essas novas riquezas conquistadas como modo de pensar o presente; nesse sentido é que as identifica como exemplo de uma nova mitologia, segundo ele, "sustentada pela ideologia moral da boa consciência tecnológica", e na qual os conceitos de comunidade e de ética universalista "se constroem por mero efeito de uma interatividade cibernética, democrática e mercadologicamente administrada" (Sodré, op. cit., p. 203).

\section{Tecnologias e "arquitetura da vida íntima"}

Na contramão da euforia com as quase infinitas ferramentas comunicacionais e interativas permitidas pelas tecnologias de comunicação e informação de nosso tempo, Turkle, ao construir os argumentos que sustentam seu novo livro, traz exemplos muito simples, inclusive dos modos de comunicação com sua filha Rebecca e dela, Turkle, com sua própria mãe; ela escreve, no epílogo do livro, intitulado sugestivamente The letter, duas situações bem distintas. Hoje, com a filha vivendo longe para cursar a universidade, as duas se comunicam regularmente pelo Skype; o fato é que Turkle se sente constrangida a ser breve em seus encontros com a filha, embora estes sempre sejam leves e cheios de informação. Na época da primeira imersão no Skype com a filha, a autora ativou memórias antigas e viu-se movida a 
procurar velhas caixas, onde tinha guardada a correspondência que trocara com a mãe durante seu primeiro ano de faculdade: pelo menos uma vez por semana elas escreviam longas cartas, emotivas, plenas de conflitos. Agora, ao reler aquelas páginas escritas pela mãe, ela diz: era como se "eu segurasse o seu coração em minhas mãos" (Turkle, 2011, p. 297; trad. minha).

As preocupações "caseiras" da autora ocupam no livro o mesmo espaço dos levantamentos feitos por meio da escuta clínica, bem como pelas entrevistas com crianças e jovens, igualmente com adultos (Turkle inclusive procurou outras mães de universitários e quis saber como elas se comunicavam com os filhos). Não nos estenderemos aqui em relatar os dados de todas as pesquisas da autora; desejamos apenas sintetizar as preocupações de uma investigadora que elabora seus estudos em um dos maiores centros de pesquisas tecnológicas do mundo. O que ela, em síntese, nos diz e nos ensina?

Para a autora de Alone together, nossas subjetividades parecem estar adquirindo contornos preocupantes, num tempo em que as tecnologias de informação e comunicação se apresentam para nós como "arquitetas de nossa intimidade", de uma maneira tal que lá, na second life, sempre somos melhores do que efetivamente somos; lá, podemos esconder-nos (embora estejamos cada vez mais expostos); lá, escrevemos mais do que falamos (com o outro). Talvez, sugere a autora, a grande questão é que estamos seduzidos pela tecnologia justamente porque ela toca em nossas maiores vulnerabilidades. E, sabemos, a mais forte dessas vulnerabilidades é nossa relação com a morte: pois bem, ali, na second life, não morremos de fato. Jamais.

Lembro aqui uma recente polêmica em Porto Alegre (RS), quando foi veiculado em grandes redes de tevê o comercial de uma rede de farmácias (Panvel), por ocasião do Natal de 2011. No vídeo intitulado "A história do Lilinho", as imagens contam, na voz em off do pai de uma menina de uns cinco anos, uma verdade que a filha jamais virá a saber, de acordo com o texto: o peixe Lilinho, que a menina ganhou, na realidade morreu, mas a mãe o substituiu por outro idêntico (e assim fez, sucessivamente, cada vez que um peixe morria). O pai na verdade está lendo uma carta que a menina nunca chegará a ler, "felizmente" (ele está lendo é para nós, consumidores e espectadores), porque é preciso "adiar esse sentimento terrível que a perda dá"; porque "fatalidades não são algo que criança precisa saber", porque "crianças, aliás, não deveriam saber de nada ruim" - e assim segue o texto publicitário, repleto de imagens paradisíacas, paisagens sublimes, uma menina muito doce, adultos amorosos e todos supostamente protetores do mundo infantil.

O discurso segundo o qual se deve negar qualquer frustração aos mais jovens parece ser uma tônica em nossa cultura e, penso, tem íntima relação com o debate 
trazido por Turkle, que vai relatando, como uma generosa e hábil contadora de histórias, cenas inacreditáveis de encontros com as crianças, as quais dizem tranquilamente à pesquisadora: brincar com bichos artificiais é melhor do que estar com animais de estimação "reais"; segundo os depoimentos, animais de brinquedo são mais compreensivos e amáveis, não precisam ser limpos e, principalmente, eles nunca morrem (Turkle, 2011, p. 1). Ao mesmo tempo, adolescentes e jovens falam sobre o acesso à web em seus Blackberries como o "lugar da esperança" na vida, o lugar em que a solidão pode ser descartada (idem, ibid., p. 3). Da mesma forma, a autora vai mostrando, por meio de uma infinidade de observações e depoimentos que coletou, o quanto estão se alterando nossas percepções do que seja estar com o outro, do que seja desejar ou não algo autêntico, a ponto de ela encontrar, na pesquisa, o "sentimento" de que seria melhor lidar com "cópias", com robôs, com simulacros - já que aqueles jovens estudantes, nativos digitais, aprenderam, por exemplo, que é possível reproduzir os movimentos, as cores e as formas de um cágado, sem a necessidade de que bichos "reais" estejam, digamos, num museu; afinal, cágados vivos sujam o ambiente, são muito inconvenientes (p. 4).

Ora, isso se estende quase que "naturalmente" às questões que envolvem os relacionamentos afetivos, com a defesa contundente de estudiosos como David Levy (citado pela autora), o qual fala em seus escritos sobre a tendência a considerar que o amor com robôs poderá se tornar tão normal como o relacionamento com outros seres humanos - argumentando que os robôs também são o "outro" para qualquer um de nós e têm a vantagem de não sofrerem ataques do coração, e assim por diante (Levy apud Turkle, 2011).

Para Turkle, o que estaríamos gradativamente aprendendo é, em primeiro lugar, uma espécie de estética da inautenticidade e da negação da surpresa; desaparece do horizonte tanto o prazer (ou o susto) do inesperado, quanto a possibilidade do desapontamento, da frustração. Ora, argumenta a autora, uma relação afetiva e a vida com o outro têm a ver com um misto de história, biologia, trauma, alegrias, expectativas, decepções, riscos, frustração, morte. Tudo isso tem a ver com a preservação e o cuidado com a intimidade. As práticas cotidianas, segundo as quais muitas vezes substituímos um simples telefonema por um "torpedo" enviado pelo celular, tornam-se cada vez mais comuns. Não duvidamos que essas práticas sejam bastante objetivas, que facilitam nossas vidas. Mas entendemos, com Turkle, que elas têm relação direta com uma discursividade que assumimos como verdade para nós, calcada na ideia de que a voz ao vivo talvez nos frustre, ou que nós mesmos possamos desapontar o outro. A negação da alteridade, do choque com aquele que é radicalmente distinto e diferente de nós, alimenta-se de todo um arsenal tecnológico, que nos protege do enfrentamento por vezes doloroso com o outro. Dito de modo diverso: as mensagens instantâneas, o Twitter, os e-mails, o ato de teclar compulsivamente 
no Facebook, tudo isso parece estar redesenhando as fronteiras entre intimidade e solidão (Turkle, 2011).

\section{Uma ética do ciberespaço?}

Em tempos chamados de pós-modernos, de decomposição de velhos e gastos valores liberais, de efetivo vazio de representação política, não podemos nos furtar a um pensamento sobre que tipo de relações éticas estamos construindo hoje. Essa é a tônica da argumentação de Muniz Sodré em seu livro, especialmente quando nos fala na discursividade dos governos (não só no Brasil), sobre a necessidade, por exemplo, de reduzir os gaps tecnológicos entre grupos sociais, regiões geográficas, países, classes (Sodré, 2011). O problema estaria não nesse sonho de uma democracia tecnológica, mas numa utopia que se constrói basicamente em torno da realidade tecnológica, em torno de um ethos político do ciberespaço (idem, ibid.).

A filósofa Marilena Chauí, por sua vez, diria que as questões trazidas por Turkle e Sodré estão, de fato, no cerne de inquietações filosóficas fundamentais. Tudo isso tem a ver com produção (ou com negação de produção) de pensamento. Apoiada em um de seus pensadores prediletos, Merleau-Ponty, Chauí (em palestra feita para o programa de tevê Café Filosófico, em 2010, sob o título “Espaço, tempo e o mundo virtual") parte da fenomenologia da percepção para sublinhar que somos, basicamente, seres temporais, e que "o tempo existe porque nós existimos", justamente porque nosso corpo é nosso modo fundamental de ser e estar no mundo (Chauí, 2012). A partir de toda uma argumentação filosófica, ela se pergunta: “O que se passa quando a espacialidade e a temporalidade do nosso corpo e da nossa experiência se perdem na atopia, ou seja, na ausência de lugar, ausência de espaço, e na acronia, isto é, na ausência do tempo" - próprias de uma sociedade calcada na cultura digital? Ora, diz ela, "são duas ausências, a atopia e a acronia, que caracterizam o mundo virtual. É isso que é o mundo virtual. É um mundo sem espaço e sem tempo" (idem, ibid.).

Chauí nos ajuda a pensar mais densamente sobre os dados e as observações de Turkle, quando retoma as ideias de Luiz Alberto Oliveira, cosmólogo brasileiro que se pergunta sobre uma ética - na perspectiva de Spinoza -, que possa determinar quais seriam, hoje, nossas novas estratégias de ação, a partir de valores que favoreçam efetivamente a vida, num tempo em que temos o homem praticamente fundido às máquinas. Ele pergunta: "Estará em ação uma nova síntese integradora da Vida, uma nova etapa de individuação do Homem?" (Oliveira, 2012).

Esse mesmo estudioso, conforme citado por Chauí, nos diz que os conceitos básicos hoje não são mais os de substância e indivíduo, mas os de informação e 
processo. Chauí o cita: “a noção de informação prescinde de qualquer suporte particular"; "temos sempre fluxos de informação operando uns sobre os outros, sintetizando-se, fragmentando-se, recombinando-se sem cessar", independente de se tratar de circuitos de microchips ou da sequência de bases de uma molécula de DNA (Oliveira apud Chauí, 2012). Se antes pensávamos com base na estrutura, na organização, na integração funcional das coisas e do mundo, hoje operamos com a categoria da informação, a qual se articula à ideia de autômato. Chauí nos diz - com apoio em Adam Shaft - que, com as revoluções industriais, vimos que nosso corpo se estendeu no espaço - McLuchan, (1996), aliás, sintetizou isso na obra cujo título diz tudo: Os meios de comunicação como extensões do homem. "Agora [diz Chauí, op. cit.], com os satélites e a informática, é nosso cérebro ou nosso sistema nervoso central que se expande sem limites, diminuindo distâncias espaciais e intervalos temporais, até abolir o espaço e o tempo". E complementa: "Com a revolução informática, estamos diante de uma nova inserção do saber e da tecnologia no modo de produção capitalista" (idem, ibid.).

O questionamento básico de Chauí é o que se refere à volatilidade e à efemeridade da vida, de modo que "nossa experiência desconhece qualquer sentido de continuidade e se esgota num presente reduzido a um instante fugaz" (idem, ibid.). Para a filósofa, o virtual não se opõe ao real, ele é o real - da mesma forma que o dizem as crianças entrevistadas por Turkle a respeito dos animais de brinquedo. $\mathrm{O}$ mito da cooperação, com base nas tecnologias digitais de comunicação e informação, é exemplificado por Chauí, fazendo referência às empresas que convidam seus empregados a cooperarem entre si, por meio do uso dos recursos computacionais, num processo de organização empresarial que redesenha as relações coletivas entre os funcionários, sem que ninguém precise encontrar-se efetivamente com qualquer pessoa. Em síntese, Chauí se pergunta sobre estes tempos de acronia e atopia, "de desmontagem do nosso corpo como ser sensível e como ser simbólico": Será que um novo ser humano está surgindo? Ele nascerá de "um campo sem simbolização, sem espaço, sem tempo e sem corpo? Será tudo virtual?" (idem, ibid.).

Todas as mídias, convergentes entre si, sempre em conexão e em tempo real, parecem ser a tônica de nossas vidas; constituem uma nova ordem social, como diz Sodré (2011), "organicamente constituída por informação", oferecendo-nos um espaço que acaba sendo, ele mesmo, a própria informação. Contudo, como lembra o autor, mesmo que essa mitologia da informação - sempre em mutação, em movimento, viva em qualquer tempo e lugar, simultânea, aberta e móvel - se afirme como hegemônica, ela convive com outros desejos e projetos, como os de preservar certos modos de vida, recuperar antigas formas de relação comunitárias, e assim por diante. Foucault diria que se trata de lutas, lutas discursivas (e, nessa condição, também políticas), em que estão em jogo verdades e práticas institucionais que ora se complementam, ora se confrontam fortemente. 
No campo educacional, lutamos já há algumas décadas num embate entre o amor às tecnologias per se e o desejo de pensá-las de modo mais problematizador, no sentido de discutir, como faz o pesquisador Antônio Zuin, o que se passa com a educação, em meio às práticas cotidianas de comunicação e informação, dos mais jovens (sobretudo deles), quando o espaço que habitam é um espaço virtual ilimitado (Zuin, 2012). Ao analisar as práticas de jovens nas redes sociais, expondo um elo muitas vezes violento entre professores e alunos, Zuin nos provoca - ao contrário do que se poderia pensar (ao termos contato com o ódio expresso nas postagens dos estudantes a respeito dos educadores) -, sugerindo que esteja aí um possível desejo juvenil, paradoxalmente, de maior proximidade dos alunos com seus mestres. $\mathrm{Ou}$ seja, como conclui Zuin (op. cit., p. 248), "o jogo pedagógico poderia ser qualitativamente diferente", inversamente ao que vem se constituindo, nas repetidas cenas de agressão no ambiente escolar.

Colocamos Sodré em diálogo com Zuin: o estudioso da comunicação questiona a fácil delegação dos saberes às máquinas, tão comum até em nossas conversas cotidianas, sobre um depósito (os sites da internet) em que todos os saberes estariam disponíveis - o que, para alguns, dispensaria a suposta figura detentora do conhecimento: o professor. Acontece que nosso tempo parece exigir outras configurações, outro lugar - político e ético - para o profissional da educação. O próprio termo "presença" vai além de significar a simples ocupação de um espaço físico; trata-se, como escreve Sodré (op. cit., p. 101), de "um lugar marcado pela radicalidade humana - que leve o indivíduo à aprendizagem da espera, à moderação da vontade ativista, à libertação de si mesmo por progressiva desidentificação frente às mecânicas injunções do ethos".

\section{Para concluir}

Talvez o trabalho de pensamento exigido de nós, hoje, seja o que se refere às potencialidades dos modos de relação dos indivíduos com os sistemas informacionais disponíveis, sob formas tão variadas. Quais seriam as possibilidades? Chauí (2010), por exemplo, vê a democracia como uma força capaz de se opor à banalização da ideia de um "mundo tranquilo, angélico e de luz", que caracterizaria o ciberespaço. Como Turkle, a filósofa não deixa de apostar numa utopia. E utopia tem a ver com criação, com arte, com pensamento. Contra o medo e o anúncio permanente de catástrofes, Chauí acredita que não podemos agir a partir de sentimentos retrógrados e conservadores (invalidando, portanto, conquistas importantíssimas da ciência e da tecnologia). Talvez precisemos de alguns anos ainda para nos distanciarmos do fascínio por um tempo e um espaço virtuais, que se mostram aparentemente sem obstáculos para nós. 
Como o peixe Lilinho da peça publicitária da rede de farmácias no sul do Brasil, como os cágados do museu em Nova York, como os companheiros de quarto das universitárias norte-americanas, como qualquer relação em que esteja em jogo o outro, face a face, como as enunciações agressivas dos alunos nas redes sociais, o fato é que morremos, vivemos, contestamos, duvidamos, entramos em conflito; o fato é que nos alegramos, e também nos desapontamos. Turkle aposta, como vimos, na prosaica possibilidade de estabelecer outras formas de contato com sua filha (combinou com ela de escrever e enviar uma carta pelo correio normal, como relata no livro). Chauí, por sua vez, responde aos que lhe indagaram, ao final da palestra no Café Filosófico: "as possibilidades de encontrar caminhos e respostas aparecem (...) no campo das artes. Então, é contar com os artistas, porque eles sempre trazem o novo, para a gente pensar e para a gente entender". E continua, referindo-se a outro modo de criação, que é o trabalho do pensamento:

Ele [o trabalho do pensamento] é um trabalho de desvendamento. De perceber o que não se sabia e de apreender e acrescentar ao que já se sabia. Ele é também um trabalho de desapontamento e de decepção, que é o suportar o instante da ignorância, o instante de não saber e de não descobrir uma resposta, uma solução. Então tudo isso é o trabalho do pensamento. Eu tenho dúvida se (...) com a solução instantânea, se apertar o botão e levar o mouse e a resposta aparecer e você simplesmente reproduzir, [se acontece algo] com o trabalho do pensamento. De duas uma: ou o trabalho do pensamento vai se realizar em outras coisas que não mais a escola ou, durante um longo período, até que as contradições arrebentem isso, durante um bom período nós não vamos ter trabalho do pensamento.

O convite de Chauí, diante das "mitologias" destes tempos - aficcionados na vida a distância, na multiplicação quase ao infinito das possibilidades de acesso à informação e à comunicação com quem quer que seja -, insiste no esforço de imaginar, de pensar; em suma, de criar. Tal esforço inicia justamente com o ato de depositar um olhar cuidadoso sobre o que a própria filósofa chamou de "processos de instituição mítica das significações", no mundo audiovisual e informatizado de nossos tempos, e que tanto aprendemos a amar. Essa frase está no prefácio escrito por Chauí ao livro de Eugênio Bucci e Maria Rita Kehl (2004) - não por acaso intitulado Videologias -, também em homenagem à obra de Barthes, autor que não cessa de provocar e sugerir formas de resistência em relação a tudo aquilo que insiste em cristalizar-se como fala mítica - na política, na cultura, especialmente na educação.

\section{Referências}

BARTHES, R. Mitologias. Trad. Rita Buongermino, Pedro de Souza e Rejane Janowitzer. Rio de Janeiro: Difel, 2009. 
BENJAMIN, W. A obra de arte na era de sua reprodutibilidade técnica. In: BENJAMIN, W. Magia e técnica, arte e política. Trad. Sergio Paulo Rouanet. São Paulo: Brasiliense, 1993a. (Obras escolhidas, v. 1). p.165-196.

BENJAMIN, W. O narrador: considerações sobre a obra de Nikolai Leskov. In: BENJAMIN, W. Magia e técnica, arte e política. Trad. Sergio Paulo Rouanet. São Paulo: Brasiliense, 1993b. (Obras escolhidas, v. 1). p. 197-221.

BUCCI, E.; KEHL, M.R. Videologias: ensaios sobre televisão. São Paulo: Boitempo, 2004.

CHAUÍ, M. Espaço, tempo e o mundo virtual. Café Filosófico. São Paulo, TV Cultura, 2 de setembro de 2010. Programa de TV. Disponível em: <http://www.cpflcultura. com.br/site/2011/11/29/espaco-tempo-e-mundo-virtual-a-contracao-do-tempo-e-oespaco-do-espetaculo-\%E2\%80\%93-marilena-chaui-e-olgaria-matos-2/>. Acesso em: 25 mar. 2012.

ECO, U. Apocalípticos e integrados. Trad. Pérola de Carvalho. São Paulo: Perspectiva, 2008.

FOUCAULT, M. Nietzsche, a genealogia, a história. In: FOUCAULT, M. Arqueologia das ciências e história dos sistemas de pensamento. Trad. Elisa Monteiro. Rio de Janeiro: Forense Universitária, 2009. (Ditos \& escritos, v. 2). p. 260-281.

FOUCAULT, M. Sobre a genealogia da ética: uma revisão do trabalho em curso. In: DREYFUS, H.; RABINOW, P. Michel Foucault, uma trajetória filosófica: para além do estruturalismo e da hermenêutica. Trad. Antonio Cavalcanti Maia. Rio de Janeiro: Forense, 2010. p. 296-327.

HEIDEGGER, M. Ensaios e conferências. Trad. de Emmanuel Carneiro Leão. Petrópolis: Vozes, 2002.

JAY, M. Cantos de experiência: variaciones modernas sobre um tema universal. Trad. Gabriela Ventureira. Buenos Aires: Paidós, 2009.

MACHADO, A. Máquina e imaginário: o desafio das poéticas tecnológicas. São Paulo: Edusp, 1996.

MCLUHAN, M. Os meios de comunicação como extensões do homem. Trad. Décio Pignatari. São Paulo: Cultrix, 1996.

OLIVEIRA, L.A. Nanotecnologia assemelha homens e máquinas. Entrevista à revista ComCiência. Disponível em:<http://www.comciencia.br/entrevistas/nanotecnologia/ oliveira.htm>. Acesso em: 14 abr. 2012.

RODRÍGUEZ, P. Prólogo: El modo de existência de uma filosofia nueva. In: SIMONDON, G. El modo de existencia de los objetos técnicos. Trad. Margarita Martínez e Pablo Rodríguez. Buenos Aires: Prometeo, 2007. p. 9-24. 
"Mitologias" em torno da novidade tecnológica em educação

SIMONDON, G. El modo de existencia de los objetos técnicos. Trad. Margarita Martínez e Pablo Rodríguez. Buenos Aires: Prometeo, 2007.

SODRÉ, M. Antropológica do espelho. Petrópolis: Vozes, 2011.

TURKLE, S. Alone together. New York: Basic Books, 2011.

ZUIN, A.A.S. Violência e tabu entre professores e alunos: a internet e a reconfiguração do elo pedagógico. São Paulo: Cortez, 2012.

Recebido em 16 de setembro de 2012.

Aprovado em 18 de outubro de 2012. 